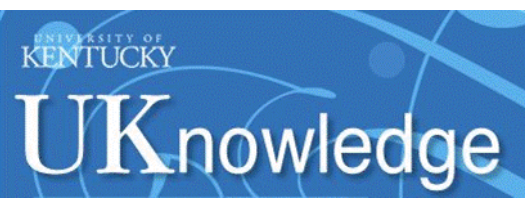

University of Kentucky

UKnowledge

2013

\title{
Gap Acceptance Parameters for HCM 2010 Roundabout Capacity Model Applications in Italy
}

\author{
A. Gazzarri \\ University of Pisa, Italy \\ Michael T. Martello \\ University of Kentucky \\ Antonio Pratelli \\ University of Pisa, Italy \\ Reginald R. Souleyrette \\ University of Kentucky, souleyrette@uky.edu
}

Follow this and additional works at: https://uknowledge.uky.edu/ce_facpub

Part of the Civil Engineering Commons

Right click to open a feedback form in a new tab to let us know how this document benefits you.

\section{Repository Citation}

Gazzarri, A.; Martello, Michael T.; Pratelli, Antonio; and Souleyrette, Reginald R., "Gap Acceptance Parameters for HCM 2010 Roundabout Capacity Model Applications in Italy" (2013). Civil Engineering Faculty Publications. 1.

https://uknowledge.uky.edu/ce_facpub/1

This Book Chapter is brought to you for free and open access by the Civil Engineering at UKnowledge. It has been accepted for inclusion in Civil Engineering Faculty Publications by an authorized administrator of UKnowledge. For more information, please contact UKnowledge@lsv.uky.edu. 


\section{Gap Acceptance Parameters for HCM 2010 Roundabout Capacity Model Applications in Italy}

Digital Object Identifier (DOI)

http://dx.doi.org/10.2495/978-1-84564-764-3/01

\section{Notes/Citation Information}

Published in Intersections Control and Safety. A. Pratelli, (Ed.). p. 1-16.

The copyright holder has granted the permission for posting the book chapter here. 


\title{
Gap acceptance parameters for HCM 2010 roundabout capacity model applications in Italy
}

\author{
A. Gazzarri ${ }^{1}$, M. T. Martello ${ }^{2}$, A. Pratelli ${ }^{1} \&$ R. R. Souleyrette ${ }^{2}$ \\ ${ }^{1}$ Department of Civil Engineering, University of Pisa, Italy \\ ${ }^{2}$ Department of Civil Engineering, University of Kentucky, USA
}

\begin{abstract}
This paper deals with the field data observation and successive application of estimation procedures in order to estimate follow-up headway and critical headway at roundabouts. Average follow-up headway and average critical headway are two key parameters in the new roundabout capacity model presented in the 2010 edition of the Highway Capacity Manual (HCM). The HCM 2010 capacity model was developed as an exponential regression model with parameter estimates based on gap acceptance theory. Gap acceptance models are strongly affected by driver behaviour and local habits. Follow-up headways can be field measured, while critical headway cannot be obtained directly. The paper mainly aims to check if general suggested values are wellsuited also for Italy or not. There have been numerous techniques developed for estimating critical headway. In order to perform a better check of a sample of experimentally observed values, three different procedures are chosen and applied. The first is a quite popular mathematical method based on maximum likelihood technique. The second is a statistical method based on the median of the observed sample distribution. The third is a graphical method known as Raff's method. All these three methods require information about the accepted gap and the largest rejected gap for each driver. Therefore a sample of field data was recorded by digital camera and processed following the instructions suggested by NCHRP. The sample data of critical headway and follow-up headway are gathered in seven selected roundabouts located in Northern Tuscany (Italy). Our first obtained results indicate that the average critical headway is significantly lower than the values recommended by some international references. However, the average follow-up headway is only higher than that
\end{abstract}


recommended for the State of California and it is lower than that recommended by all other international references. Finally, conclusions drawn along with insights for further research developments are suggested.

Keywords: gap acceptance theory, critical headway, follow-up headway, HCM2010 roundabout capacity model, maximum likelihood, Raff's method.

\section{Introduction}

The roundabout capacity model presented in the 2010 edition of the Highway Capacity Manual (HCM 2010) [1] was developed as a non-linear empirical regression model with a theoretical basis in gap acceptance theory. It is well known that gap acceptance models are strongly affected by driver behaviour and local habits. Therefore, the HCM 2010 capacity model should be calibrated to local conditions. Two parameters that may be changed to reflect local driving behaviour are the critical headway and follow-up headway (referred to as critical gap and follow-up time in earlier studies [2]). The accuracy of capacity calculations at roundabouts is dependent largely on the accurate estimation of critical headway and follow up headway. The NCHRP Report 572 presents a set of critical headway and follow-up headway values based on a comprehensive evaluation of roundabouts throughout the United States [3]. Its recommended operational models were incorporated into the 2010 HCM. Estimates/ measurements of critical headway and follow-up headway were provided by $\mathrm{Xu}$ and Tian [2] for ten roundabouts in California. In that study, the capacity model was calibrated using these measurements. The purpose of this research project is to test the adaptability of the HCM2010 capacity model in Tuscany (Italy) and in Kentucky (USA). To achieve this goal, two alternative calibration approaches can be used: one is local gap acceptance data collection and the other is entry lane simulation. The first step of this research project was related to local data collection. Therefore, the pilot study was conducted at seven roundabouts located in Northern Tuscany collecting a field data sample and then applying three different critical headway estimation procedures. There have been numerous techniques developed for estimating the critical headway. Among these methods, there is the popular maximum likelihood technique [5]. Then, a statistical method based on the median of the observed sample distribution [10] and a graphical technique known as Raff's method [11] were applied in order to compare the previous obtained values through the maximum likelihood technique. This paper shows the results of such pilot study, which can be considered as our research project first step.

\section{HCM 2010 roundabout capacity model}

Based on a recent analysis of lane-based US field data, Chapter 21 of the 2010 Edition of the HCM presents a new roundabout's capacity model for both singlelane and multi-lane roundabout entries. This new model can be viewed both as an exponential regression model (empirical) and a gap-acceptance (theoretical) model [14]. For a single entry lane, capacity $(\mathrm{pc} / \mathrm{h})$ is expressed as: 


$$
C_{e}=A \exp \left(-B q_{c}\right)
$$

where parameters $A$ and $B$ are respectively defined as the follow-up headway (s) and critical headway (s) values:

$$
A=\frac{3600}{t_{f}} \quad B=\frac{\left(t_{c}-0.5 t_{f}\right)}{3600}
$$

In equation (1), $q_{c}$ is the conflicting (opposing) flow rate in $\mathrm{pc} / \mathrm{h}$ which is the circulating flow rate upstream of the subject entry. Both the single-lane and multi-lane capacity equations can be calibrated using local data for the critical headway and follow-up headways parameters.

It is recognized that the driver behavior is "the largest variable affecting roundabout performance" and found that "geometry in the aggregate sense (number of lanes) has a clear effect on the capacity of the roundabout entry" [3]. The HCM 2010 multi-lane capacity model was developed also for both right and left lanes of a two-lane entry. These equations are the same as (1) above, but obviously the headway parameters are now related to each specific entry lane.

HCM 2010 "default" parameters are: $B=0.0010$ for single lane (corresponding to $t_{f}=3.19 \mathrm{~s}$ and $t_{c}=5.19 \mathrm{~s}$ ) and in a two-lane entry $B=0.0007$ for right lane (corresponding to $t_{f}=3.19 \mathrm{~s}$ and $t_{c}=4.11 \mathrm{~s}$ ) or $B=0.00075$ for left lane (corresponding to $t_{f}=3.19 \mathrm{~s}$ and $t_{c}=4.29 \mathrm{~s}$ ).

\section{Data collection and extraction}

Data collection was carried out on seven existing roundabouts using digital video cameras placed at the center of the central island during weekday peak periods. Flows of vehicles circulating on the ring and entering in the roundabout were recorded when high traffic volumes were actually observed. A continuous queue on the entrance of each branch was required in order to have a considerable number of follow-up headways, while intense heavy flow on the ring was needed to obtain a significant number of drivers who rejected at least one headway before entering the roundabout. Sites were selected on the basis of several geometric combinations (single-lane, multi-lane) and land use (residential, commercial, industrial) in order to measure headways related to several types of drivers.

Experimental observations at multi-lane roundabout have shown that drivers are conditioned by the conflicting flow of both lanes in the ring: therefore, this flow was assumed unique and was not considered separately for each lane in the ring. This assumption was made also in other studies [2,3]. The studied roundabouts are located in some cities of the Northern part of Tuscany (Italy): Pisa, Viareggio, Camaiore, Massa, Pietrasanta, Carrara and Lucca. Data collection sites are summarized in Table 1. Headway data were extracted later from the recorded videos.

Three time events were recorded: the time at which an entering vehicle stopped at the stop line, the passage times of circulating vehicles that directly 
Table 1: $\quad$ Summary of roundabout data collection locations.

\begin{tabular}{|c|c|c|c|c|c|}
\hline City & Location & $\begin{array}{c}\text { Inscribed } \\
\text { Circle Diam. }\end{array}$ & $\begin{array}{l}\text { Entry } \\
\text { Lanes }\end{array}$ & Branch & Date and Time \\
\hline Pisa & $\begin{array}{l}\text { V. Paparelli } \\
\text { V. Pratale }\end{array}$ & $\begin{array}{l}180 \mathrm{ft} \\
(55 \mathrm{~m})\end{array}$ & 1 & South & $\begin{array}{l}\text { 18/11/2011Tues. } \\
\text { 06:20-07:20 pm }\end{array}$ \\
\hline Viareggio & $\begin{array}{l}\text { V. Aurelia } \\
\text { V. Polo }\end{array}$ & $\begin{array}{l}92 \mathrm{ft} \\
(28 \mathrm{~m})\end{array}$ & 1 & West & $\begin{array}{c}\text { 19/11/2011Sat. } \\
12: 15-12: 50 \mathrm{am}\end{array}$ \\
\hline Viareggio & $\begin{array}{l}\text { V. Aurelia } \\
\text { V. Polo }\end{array}$ & $\begin{array}{l}92 \mathrm{ft} \\
(28 \mathrm{~m})\end{array}$ & 1 & North & $\begin{array}{c}19 / 11 / 2011 \mathrm{Sat} \\
12: 15-12: 50 \mathrm{am}\end{array}$ \\
\hline Camaiore & $\begin{array}{l}\text { V. Sarzanese } \\
\text { V. Italica }\end{array}$ & $\begin{array}{l}122 \mathrm{ft} \\
(37 \mathrm{~m})\end{array}$ & 1 & East & $\begin{array}{c}\text { 06/12/2011Tues. } \\
\text { 07:30-08:05am }\end{array}$ \\
\hline Massa & $\begin{array}{l}\text { V. Avenza } \\
\text { V. Mattei }\end{array}$ & $\begin{array}{l}122 \mathrm{ft} \\
(37 \mathrm{~m})\end{array}$ & 2 & East & $\begin{array}{l}\text { 08/12/2011Thur. } \\
\text { 05:50-06:45 pm }\end{array}$ \\
\hline Pietrasanta & $\begin{array}{l}\text { V. Maggio } \\
\text { V. Aurelia }\end{array}$ & $\begin{array}{l}161 \mathrm{ft} \\
(49 \mathrm{~m})\end{array}$ & 2 & West & $\begin{array}{l}\text { 21/12/2011Wed. } \\
\text { 05:50-06:45 pm }\end{array}$ \\
\hline Carrara & $\begin{array}{l}\text { V. Settembre } \\
\text { V. Covetta }\end{array}$ & $\begin{array}{l}111 \mathrm{ft} \\
(34 \mathrm{~m})\end{array}$ & 2 & North & $\begin{array}{l}\text { 10/01/2012Tues. } \\
\text { 06:40-07:40 pm }\end{array}$ \\
\hline Lucca & $\begin{array}{l}\text { V. Carducci } \\
\text { V. Europa }\end{array}$ & $\begin{array}{l}144 \mathrm{ft} \\
(44 \mathrm{~m})\end{array}$ & 2 & North & $\begin{array}{l}\text { 23/01/2012Mon. } \\
\text { 04:10-05:00 pm }\end{array}$ \\
\hline Lucca & $\begin{array}{l}\text { V. Carducci } \\
\text { V. Europa }\end{array}$ & $\begin{array}{l}144 \mathrm{ft} \\
(44 \mathrm{~m})\end{array}$ & 2 & East & $\begin{array}{l}\text { 23/01/2012Mon. } \\
\text { 04:10-05:00 pm }\end{array}$ \\
\hline
\end{tabular}

conflicted with the entering vehicle, and the time when the entering vehicle left the stop line. The passage times of circulating vehicles define the start and end of major stream headways that were either accepted or rejected by the entering vehicles.

The definition of headways from NCHRP 572 was used in this paper [3].

The procedure for extracting video data required the following steps: display the movie using the Quick Time Player ${ }^{\mathrm{TM}}$ software in order to record the frame number for the event of interest (see Fig. 1); record the frame number on an Excel worksheet; and, review the movie once for each event of interest.

\section{Data analysis}

Accepted headways, maximum rejected headways and follow-up headways were calculated in the worksheet. Headways were determined by counting frames between successive vehicles (25 frames per second per EU standards). Next, three different procedures were applied in order to estimate critical headways and a comparison was carried out between the resulting values. Finally, the follow-up headways were computed directly.

\subsection{Critical headway}

Critical headway represents the minimum time interval in the circulating flow when an entering vehicle can safely enter a roundabout [2]. In general, critical headway is a parameter that depends on local conditions such as geometric layout, driver behaviour, vehicle characteristics, and traffic conditions [4].

However, critical headway cannot be measured directly in the field or from recorded events. Numerous studies and techniques have been developed for 


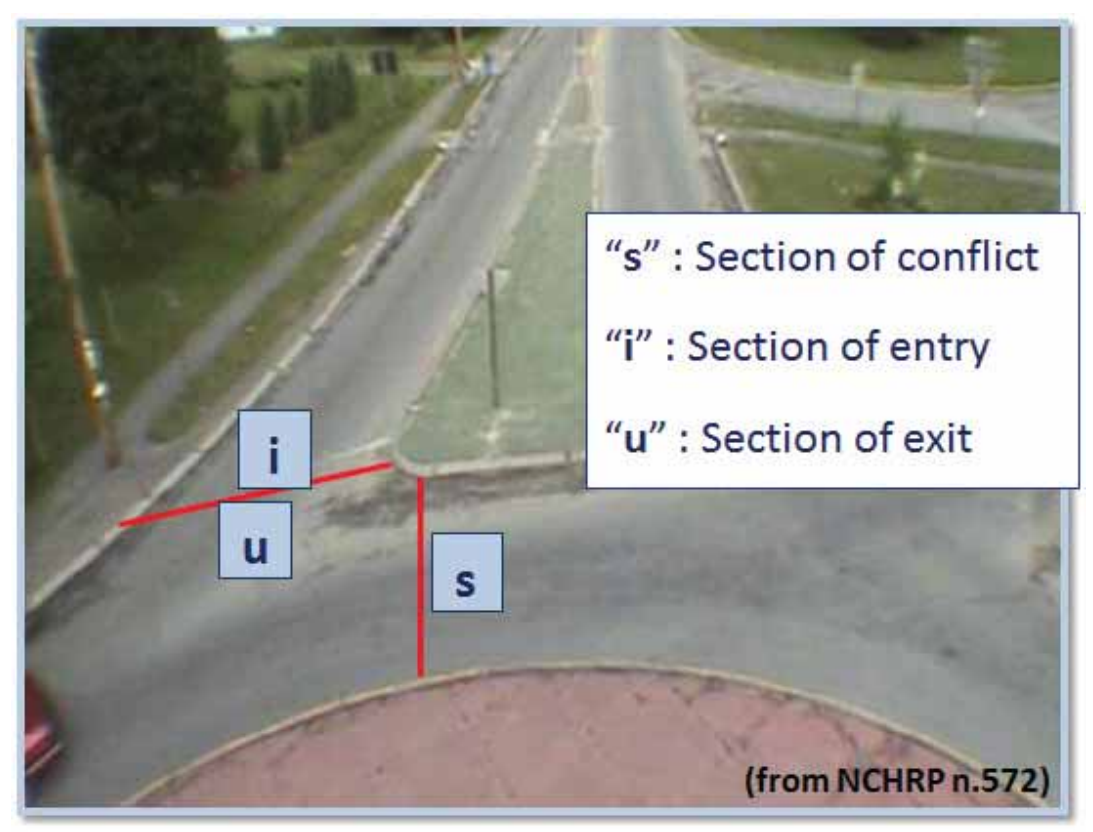

Figure 1: $\quad$ Event reference lines defined by the NCHRP 572 headways data recording procedure.

estimating critical headway. In this study, three different critical headway procedures are chosen and applied in order to compare the obtained values. These methods require information about the accepted headway and the largest rejected headway for each driver. The rejected and the accepted headways were enumerated within the Excel worksheet.

\subsubsection{Maximum likelihood method}

The maximum likelihood method [5] was used to estimate critical headway. This technique provides an estimate of the average critical headway of all the drivers by assuming that a single driver's critical headway ranges between his or her largest rejected headway and the accepted headway.

A probabilistic distribution for critical headways must be assumed. Troutbeck [6] used a Log-normal distribution, Brilon [7] used a hyper-Erlang distribution. Weinert [8] compared the results obtained from different assumptions about the type of probabilistic distribution: Log-normal, Weibull and Erlang.

As differences in the results between various distribution assumptions were only a few thousandths of a second [8], the Log-normal distribution was assumed.

The parameters of a Log-normal function, the mean $\mu$ and variance $\sigma^{2}$, are obtained by maximizing the likelihood function. The likelihood function is defined as the probability that the critical headway distribution lies between the observed distribution of the largest rejected headways and the accepted headways. The parameters $\mu$ and $\sigma^{2}$ are obtained by maximizing this likelihood function. In this way, the distribution of critical headways, as well as their mean and variance, can be derived. A solution was found using Scilab [9] to solve the 
two equations. This way, the mean critical headway and its variance were computed. Table 2 summarizes the maximum likelihood results for critical headways for all single-lane sites. As can be seen, critical headway varies between 3.54 and 4.10 seconds (s) with a mean value of 3.86 seconds (s).

Maximum likelihood results for critical headways for all multi-lane sites are summarized in Table 3. It can be seen that critical headway for the left lane varies between 3.59 and $4.42 \mathrm{~s}$ with a mean value of $3.90 \mathrm{~s}$ and critical headway for the right lane varies between $3.19 \mathrm{~s}$ and 4.33 with a mean value of $3.69 \mathrm{~s}$.

Table 2: Critical headway results at single-lane roundabout locations.

\begin{tabular}{|l|c|c|r|}
\hline \multirow{4}{*}{ Location } & \multicolumn{3}{|c|}{ Maximum Likelihood Methodology } \\
\cline { 2 - 3 } & Mean (s) & Standard Deviation (s) & Sample Size \\
\hline Pisa & 3.80 & 0.89 & 71 \\
\hline Viareggio-West & 3.99 & 0.79 & 98 \\
\hline Viareggio-North & 4.10 & 0.95 & 47 \\
\hline Camaiore & 3.54 & 0.67 & 61 \\
\hline Average & 3.86 & 0.82 & Total =277 \\
\hline
\end{tabular}

Table 3: $\quad$ Critical headway results at multi-lane roundabout locations.

\begin{tabular}{|l|l|c|c|r|}
\hline \multicolumn{5}{|c|}{ Maximum Likelihood Methodology } \\
\hline \multirow{2}{*}{ Location } & \multirow{2}{*}{ Lane } & \multicolumn{2}{|c|}{ Critical Headway } & \multirow{2}{*}{ Sample Size } \\
\cline { 3 - 5 } & & Mean (s) & Standard Deviation (s) & \\
\hline \multirow{2}{*}{ Massa } & Left & 4.05 & 0.81 & 62 \\
\cline { 2 - 5 } & Right & 4.33 & 1.08 & 59 \\
\hline \multirow{2}{*}{ Pietrasanta } & Left & 3.59 & 0.64 & 53 \\
\cline { 2 - 5 } & Right & 3.50 & 0.80 & 51 \\
\hline \multirow{2}{*}{ Carrara } & Left & 4.42 & 1.14 & 56 \\
\cline { 2 - 5 } & Right & 3.85 & 0.88 & 54 \\
\hline \multirow{2}{*}{ Lucca-North } & Left & 3.71 & 0.75 & 82 \\
\cline { 2 - 5 } & Right & 3.56 & 0.61 & 69 \\
\hline \multirow{2}{*}{ Lucca-East } & Left & 3.71 & 0.99 & Total L. $=302$ \\
\cline { 2 - 5 } & Right & 3.19 & 0.80 & Total R. $=263$ \\
\hline Average & Left & 3.90 & 0.87 & 0.83 \\
\hline
\end{tabular}

\subsubsection{Median method}

A statistical method, based on the median of the observed distribution, known as the median method [10], was used to estimate critical headway. This method assumes that the best estimate of critical headway for each driver is the average of the largest rejected headway and the accepted headway.

The value of critical headway thus obtained for each driver was recorded in size classes of 0.5 seconds. In this way, a histogram was constructed: the $\mathrm{x}$-axis contains the classes of critical headways and the y-axis reports the frequencies. Therefore, the class containing the median of the distribution was determined; finally, the critical headway of the sample was estimated within this class, 
assuming a linear trend. Results of the critical headway measurements of all the sites are summarized in Tables 8 and 9.

The critical headways for the four single-lane sites obtained by this method varies between 3.58 and $3.97 \mathrm{~s}$ with a mean value of $3.86 \mathrm{~s}$, while the critical headways of all the multi-lane sites for the left lane varies between 3.64 and 4.18 $\mathrm{s}$ with a mean value of $3.84 \mathrm{~s}$ and the critical headway for the right lane varies between $3.23 \mathrm{~s}$ and 4.35 with a mean value of $3.74 \mathrm{~s}$.

\subsubsection{Raff's method}

A graphical method, based on Raff's definition [11], or Raff's method, was used to estimate critical headway. The concept of critical headway was used by Raff, who defined it as the gap that has the number of accepted shorter gaps equal to the number of longer rejected gaps. Using this graphical method, two cumulative distribution curves are drawn: one of them relates gap lengths $t$ with the number of accepted gaps less than $t$ and the other relates $t$ with the number of rejected gaps greater than $t$. The intersection of these two curves gives the value of $t$ for the critical headway [12]. For each observed approach, the two cumulative distribution curves are constructed. At the intersection point, each curve is a linear segment the curve is comprised of discrete points. Next, the equations of the segments that intersect are determined and the system of the equations is solved. Therefore, the value of critical headway represented by the intersection point may be determined. Results of critical headway measurements of all the sites are summarized in Tables 4 and 5.

Critical headways for the four single-lane sites obtained by this method vary between 3.28 and $3.72 \mathrm{~s}$ with a mean value of $3.50 \mathrm{~s}$, while critical headways of all the multi-lane sites for the left lane vary between 3.29 and $3.86 \mathrm{~s}$ with a mean value of $3.55 \mathrm{~s}$ and critical headway for the right lane varies between $2.82 \mathrm{~s}$ and 4.12 with a mean value of $3.38 \mathrm{~s}$.

\subsubsection{Comparison with three methods}

The results obtained by the three methods for all sites show little variation. Critical headway determined by the maximum likelihood methodology and the median method are most similar, while the values produced by Raff's method are systematically lower (as seen for example in Figure 2, relative to single-lane roundabouts and multi-lane roundabout).

The development of the median method was easier and faster than the maximum likelihood methodology, while producing quite similar results. Such trend of the median method shall be also checked in the further steps of this research project.

Tables 4 and 5 show the comparison between the results respectively obtained for each observed location in respect to the three estimation methods.

For single-lane roundabouts, critical headways estimated by the median method differ from corresponding values obtained by maximum likelihood by $-4.39 \%$ to $+4.47 \%$, while the values obtained by Raff's method are lower and differ by $-6.67 \%$ to $-11.22 \%$ (see Table 4 ). In the case of multi-lane roundabouts, critical headways estimated by the median method differ from corresponding values obtained by maximum likelihood by a percentage of 
$-5.43 \%$ to $+1.95 \%$ for the left lane, and by $-3.38 \%$ to $+5.90 \%$ for right lane. The values obtained by Raff's method are lower and differ by $-5.68 \%$ to $-12.67 \%$ for the left lane, and by $-4.85 \%$ to $+11.60 \%$ for the right lane (see Table 5 ).
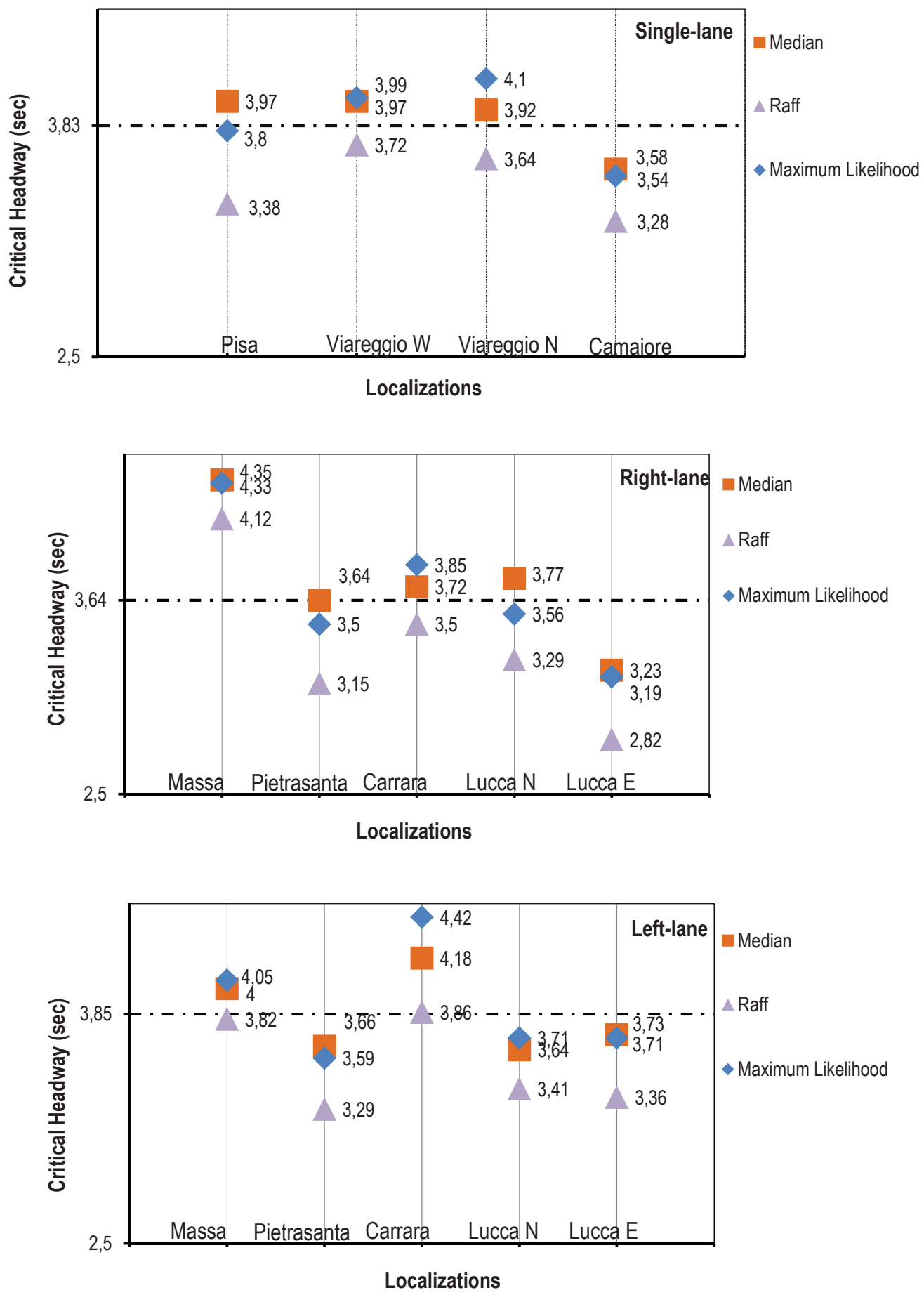

Figure 2: Results for each estimation method: comparison. 
Table 4: Critical headway results at single-lane roundabout: comparison.

\begin{tabular}{|l|c|c|c|c|c|c|}
\hline \multicolumn{7}{|c|}{ Critical Headway $($ - Single Lane } \\
\hline Location & Median & Likelihood & $\%$ & Raff & Likelihood & $\%$ \\
\hline Pisa & 3.97 & 3.80 & +4.47 & 3.38 & 3.80 & -11.05 \\
\hline Viareggio W & 3.97 & 3.99 & -0.50 & 3.72 & 3.99 & -6.77 \\
\hline Viareggio N & 3.92 & 4.10 & -4.39 & 3.64 & 4.10 & -11.22 \\
\hline Camaiore & 3.58 & 3.54 & +1.13 & 3.68 & 3.54 & -7.34 \\
\hline
\end{tabular}

Table 5: Critical headway results at multi-lane roundabout: comparison.

\begin{tabular}{|l|c|c|c|c|c|c|}
\hline \multicolumn{7}{|c|}{ Critical Headway $(\mathrm{s})$ - Left Lane } \\
\hline Location & Median & Likelihood & $\%$ & Raff & Likelihood & $\%$ \\
\hline Massa & 4.00 & 4.05 & -1.23 & 3.82 & 4.05 & -5.68 \\
\hline Pietrasanta & 3.66 & 3.59 & +1.95 & 3.29 & 3.59 & -8.36 \\
\hline Carrara & 4.18 & 4.42 & -5.43 & 3.86 & 4.42 & -12.67 \\
\hline Lucca N & 3.64 & 3.71 & -1.89 & 3.41 & 3.71 & -8.09 \\
\hline Lucca W & 3.73 & 3.71 & +0.54 & 3.36 & 3.71 & -9.43 \\
\hline \multicolumn{7}{|c|}{} \\
\hline Location & Median & Litikelihood & $\%$ & Raff & Likelihood & $\%$ \\
\hline Massa & 4.35 & 4.33 & +0.46 & 4.12 & 4.33 & -4.85 \\
\hline Pietrasanta & 3.64 & 3.50 & +4.00 & 3.15 & 3.50 & -10.00 \\
\hline Carrara & 3.72 & 3.85 & -3.38 & 3.50 & 3.85 & -9.09 \\
\hline Lucca N & 3.77 & 3.56 & +5.90 & 3.29 & 3.56 & -7.58 \\
\hline Lucca W & 3.23 & 3.19 & +1.25 & 2.82 & 3.19 & -11.60 \\
\hline
\end{tabular}

Table 6: $\quad$ Follow-up headway results at single-lane roundabout locations.

\begin{tabular}{|l|c|c|r|}
\hline \multicolumn{4}{|c|}{ Follow-up Headway $(s)$} \\
\hline Location & Mean $(s)$ & Standard Deviation $(s)$ & Sample Size \\
\hline Pisa & 2.59 & 0.90 & 500 \\
\hline Viareggio - West & 2.65 & 0.69 & 155 \\
\hline Viareggio - North & 2.76 & 0.68 & 190 \\
\hline Camaiore & 2.52 & 0.80 & 226 \\
\hline Average & 2.63 & 0.77 & Total $=1071$ \\
\hline
\end{tabular}

\subsection{Follow-up headway}

Follow-up headway is the minimum headway between two entering vehicles, which can be calculated by the average difference between the passage times of two entering vehicles accepting the same mainstream gap under a queued condition [2]. Follow-up headways were computed from recorded time events. Once the individual follow up headway was obtained, the mean and standard deviation were calculated. Table 6 summarizes critical headway results for the four single-lane locations. As can be seen, the follow-up headway varies between 2.52 and $2.76 \mathrm{~s}$ with a mean value of $2.63 \mathrm{~s}$. Results of the follow-up headway 
measurements of all the multi-lane sites are summarized in Table 7. It can be seen that the follow-up headway for the left lane varies between 2.16 and $3.10 \mathrm{~s}$ with a mean value of $2.65 \mathrm{~s}$ and the follow-up headway for the right lane ranges between $2.44 \mathrm{~s}$ and 2.91 with a mean value of $2.64 \mathrm{~s}$. The mean value obtained for the follow-up headways in both lanes is almost the same.

Table 7: $\quad$ Follow-up headway results at multi-lane roundabout locations.

\begin{tabular}{|l|l|c|c|r|}
\hline \multicolumn{5}{|c|}{ Follow-up Headway $(s)$} \\
\hline \multirow{2}{*}{ Masation } & \multirow{2}{*}{ Lane } & \multirow{2}{*}{ Mean $(s)$} & Standard Deviation $(s)$ & \multirow{2}{*}{ Sample Size } \\
\hline \multirow{2}{*}{ Pietrasanta } & Left & 3.10 & 0.95 & 145 \\
\cline { 2 - 5 } & Right & 2.70 & 0.71 & 205 \\
\cline { 2 - 5 } & Left & 2.16 & 0.49 & 57 \\
\hline \multirow{2}{*}{ Carrara } & Reft & 2.44 & 0.58 & 59 \\
\cline { 2 - 5 } & Right & 2.77 & 0.72 & 143 \\
\hline \multirow{2}{*}{ Lucca-North } & Left & 2.91 & 0.76 & 82 \\
\cline { 2 - 5 } & Right & 2.58 & 0.61 & 124 \\
\hline \multirow{2}{*}{ Lucca-East } & Left & 2.56 & 0.61 & 92 \\
\cline { 2 - 5 } & Right & 2.59 & 0.66 & Total L. $=467$ \\
\hline Average & Left & 2.65 & 0.69 & Total R. $=556$ \\
\hline
\end{tabular}

\section{First experimental results}

The results obtained through the three estimation methods for all sites show little differences. The maximum likelihood method has been also previously applied by several authors, and these values are herewith considered for later comparisons. Therefore, our average critical headway obtained by the maximum likelihood method was compared to such international referenced values.

The first experimental results for critical headway are summarized as follows. For single-lane roundabout, critical headway ranges between 3.54 and $4.10 \mathrm{~s}$ with a mean of $3.86 \mathrm{~s}$ and with an average weighted on the inverse of the standard deviation of $3.83 \mathrm{~s}$. In the case of multi-lane roundabout, the critical headway obtained for left lane varies between 3.59 and $4.42 \mathrm{~s}$ with a mean of $3.90 \mathrm{~s}$ and with an average weighted on the inverse of the standard deviation of $3.85 \mathrm{~s}$; while, critical headway obtained for right lane varies between 3.19 and $4.33 \mathrm{~s}$ with a mean of $3.69 \mathrm{~s}$ and with an average weighted on the inverse of the standard deviation of $3.64 \mathrm{~s}$. The weighted average was calculated in function of the inverse of the standard deviation so that the smaller values of the standard deviation carry the same weight as larger values. Moreover, as the average critical headway and weighted average critical headway are quite similar. Therefore, the average critical headway was assumed equal to the weighted average critical headway. The average critical headway for each type of lane is summarized in Table 8. The first experimental results for follow-up headway are summarized as follows. For single-lane roundabouts, the follow-up headway 
obtained ranges between 2.52 and $2.76 \mathrm{~s}$ with a mean of $2.63 \mathrm{~s}$ and with an average weighted on the inverse of the standard deviation of $2.64 \mathrm{~s}$. In the case of multi-lane roundabout, critical headway obtained for left lane varies between 2.16 and $3.10 \mathrm{~s}$ with a mean of $2.65 \mathrm{~s}$ and with an average weighted on the inverse of the standard deviation of $2.59 \mathrm{~s}$. While, critical headway obtained for right lane varies between 2.44 and $2.91 \mathrm{~s}$ with a mean of $2.64 \mathrm{~s}$ and with an average weighted on the inverse of the standard deviation of $2.63 \mathrm{~s}$. Also in this case, the weighted average was calculated in function of the inverse of the standard deviation for the same reason as explained above. Moreover, the average follow-up headway and weighted average follow-up headway are much similar. Therefore, the average follow-up headway for this study was assumed equal to the weighted average follow-up headway. The average follow-up headway for each type of lane is summarized in Table 8.

Table 8: $\quad$ Average critical headway and average follow-up headway.

\begin{tabular}{|c|c|c|c|c|c|}
\hline \multicolumn{6}{|c|}{ Average Critical Headway (s) } \\
\hline \multirow{2}{*}{\multicolumn{2}{|c|}{ Roundabout }} & \multicolumn{2}{|c|}{ North Tuscany } & \multicolumn{2}{|c|}{ California } \\
\hline & & \multirow{2}{*}{$\begin{array}{c}\text { Mean (s) } \\
3.83\end{array}$} & \multirow{2}{*}{$\begin{array}{c}\text { Standard } \\
\text { Deviation }(\mathrm{s}) \\
0.40\end{array}$} & \multirow{2}{*}{$\begin{array}{c}\text { Mean (s) } \\
4.85\end{array}$} & \multirow{2}{*}{$\begin{array}{c}\text { Standard } \\
\text { Deviation }(\mathrm{s}) \\
0.40\end{array}$} \\
\hline Single-lane & single & & & & \\
\hline \multirow{2}{*}{ Multi-lane } & Left & 3.85 & 0.36 & 4.74 & 0.59 \\
\hline & Right & 3.64 & 0.35 & 4.46 & 0.57 \\
\hline \multicolumn{6}{|c|}{ Average Follow-up Headway (s) } \\
\hline \multirow{2}{*}{\multicolumn{2}{|c|}{ Roundabout }} & \multicolumn{2}{|c|}{ North Tuscany } & \multicolumn{2}{|c|}{ California } \\
\hline & & Mean (s) & $\begin{array}{c}\text { Standard } \\
\text { Deviation (s) }\end{array}$ & Mean (s) & $\begin{array}{c}\text { Standard } \\
\text { Deviation (s) }\end{array}$ \\
\hline Single-lane & single & 2.64 & 0.38 & 2.45 & 0.21 \\
\hline \multirow{2}{*}{ Multi-lane } & Left & 2.59 & 0.29 & 2.20 & 0.41 \\
\hline & Right & 2.63 & 0.30 & 2.16 & 0.48 \\
\hline
\end{tabular}

\subsection{Comparison with previous studies}

In the following, the average critical headway and the average follow-up headway obtained in Tuscany were compared with the values from previous international studies. Initially, a direct comparison was carried out between this study and the similar work conducted for State of California, by Xu and Tian [2]. Then, comparisons were made between the headway results from this research and those from some international references, such as HCM 2010 [1] default capacity model, NCHRP 572 [3], and Xu and Tian [2]. Finally, a comparison of the capacity model calibration by these different studies was carried out in order to evaluate the differences in capacity calculations at roundabouts.

\subsubsection{Comparison with the study in California}

The experimental results of this study were been analyzed and compared to the California values [2]. 
Table 8 summarizes the final results for these different sources. The following observations can therefore be made:

- the average critical headway of North Tuscany's sites is always smaller than the average critical headway obtained in California, for each lane;

- the average follow up headway of North Tuscany's sites, instead, is always larger than the average follow up headway obtained in California, for each lane.

\subsubsection{Comparison with previous studies}

The results of this study have been analysed and compared with data from previous international references. Table 9 summarizes the values drawn from these different references. Based on the results, the following observations may be made:

- the average critical headway of North Tuscany's locations is always smaller than the average critical headway values drawn from international references;

- the average follow-up headway of North Tuscany's locations, also, is always smaller than the average follow-up headway suggested by HCM 2010 and NCHRP 572, for each lane, but it is larger than the average follow-up headway referred to California, for each lane.

Table 9: International references comparison.

\begin{tabular}{|l|c|c|c|}
\hline \multicolumn{4}{|c|}{ Average Critical Headway $(\mathrm{s})$} \\
\hline Lane & single & left & right \\
\hline HCM 2010 & 5.19 & 4.29 & 4.11 \\
\hline NCHRP 572 & 5.10 & 4.50 & 4.20 \\
\hline California & 4.90 & 4.80 & 4.40 \\
\hline North Tuscany & 3.83 & 3.85 & 3.64 \\
\hline \multicolumn{4}{|c|}{ Average Follow-up Headway $(\mathrm{s})$} \\
\hline Lane & single & left & right \\
\hline HCM 2010 & 3.20 & 3.20 & 3.20 \\
\hline NCHRP 572 & 3.20 & 3.40 & 3.10 \\
\hline California & 2.50 & 2.30 & 2.20 \\
\hline North Tuscany & 2.63 & 2.65 & 2.64 \\
\hline
\end{tabular}

\subsection{HCM 2010 capacity model calibration}

Local calibration of the capacity models is recommended to best reflect local driver behaviour [13]. The HCM 2010 capacity model was calibrated by using specific data for critical headway and follow up headway. Mathematical forms of the capacity model and their related parameters estimates, for each lane, are shown in Table 10.

One can observe that models resulting from the use of California-specific data and Northern Tuscany-specific data for critical headway and follow-up headway have a higher intercept, and thus a higher capacity, over their whole range when compared with any of the models based on international references. 
Table 10: $\quad$ HCM 2010 capacity model.

\begin{tabular}{|c|c|c|c|c|c|}
\hline \multicolumn{6}{|c|}{ HCM 2010 Capacity Model } \\
\hline & $t_{f}(s)$ & $t_{c}(s)$ & $A$ & $B$ & $C_{e}(p c / h)$ \\
\hline \multicolumn{6}{|c|}{ Single Lane } \\
\hline HCM 2010 & 3.19 & 5.19 & 1130 & 0.001 & $1130 * \exp \left(\left(-1 * 10^{\wedge}-3\right) * \mathrm{q}_{\mathrm{c}}\right)$ \\
\hline NCHRP 572 & 3.20 & 5.10 & 1125 & 0.000972 & $1125 * \exp \left(\left(-0.972 * 10^{\wedge}-3\right) * \mathrm{q}_{\mathrm{c}}\right)$ \\
\hline California & 2.50 & 4.90 & 1440 & 0.00101 & $1440 * \exp \left(\left(-1.01 * 10^{\wedge}-3\right) * \mathrm{q}_{\mathrm{c}}\right)$ \\
\hline North Tuscany & 2.64 & 3.83 & 1364 & 0.00070 & $1364 * \exp \left(\left(-0.70 * 10^{\wedge}-3\right) * \mathrm{q}_{\mathrm{c}}\right)$ \\
\hline \multicolumn{6}{|c|}{ Left Lane } \\
\hline HCM 2010 & 3.19 & 4.29 & 1130 & 0.00075 & $1130 * \exp \left(\left(-0.75^{*} 10^{\wedge}-3\right) * q_{c}\right)$ \\
\hline NCHRP 572 & 3.40 & 4.50 & 1059 & 0.000778 & $1059 * \exp \left(\left(-0.778 * 10^{\wedge}-3\right) * \mathrm{q}_{\mathrm{c}}\right)$ \\
\hline California & 2.30 & 4.80 & 1565 & 0.001014 & $1565 * \exp \left(\left(-1.014 * 10^{\wedge}-3\right) * \mathrm{q}_{c}\right)$ \\
\hline North Tuscany & 2.59 & 3.85 & 1390 & 0.000710 & $1390 * \exp \left(\left(-0.70 * 10^{\wedge}-3\right) * q_{c}\right)$ \\
\hline \multicolumn{6}{|c|}{ Right Lane } \\
\hline HCM 2010 & 3.19 & 4.11 & 1130 & 0.0007 & $1130 * \exp \left(\left(-0.7 * 10^{\wedge}-3\right) * \mathrm{q}_{\mathrm{c}}\right)$ \\
\hline NCHRP 572 & 3.10 & 4.20 & 1161 & 0.000736 & $1161 * \exp \left(\left(-0.736 * 10^{\wedge}-3\right) * \mathrm{q}_{\mathrm{c}}\right)$ \\
\hline California & 2.20 & 4.40 & 1636 & 0.000917 & $1636 * \exp \left(\left(-0.917 * 10^{\wedge}-3\right) * \mathrm{q}_{\mathrm{c}}\right)$ \\
\hline North Tuscany & 2.63 & 3.64 & 1369 & 0.000646 & $1369 * \exp \left(\left(-0.646 * 10^{\wedge}-3\right) * \mathrm{q}_{\mathrm{c}}\right)$ \\
\hline
\end{tabular}

Figures 3 to 5 show several capacity models for single and dual-lane roundabouts.

The Northern Tuscany model provides values of roundabout capacity greater than those provides by HCM 2010 capacity model: for example, considering a conflicting flow amounting to $400 \mathrm{pc} / \mathrm{h}$, the capacity is between $+23.80 \%$ and $+36.10 \%$ greater (see Table 11 ).

Table 11: HCM 2010 model vs. other studies: capacity.

\begin{tabular}{|l|c|c|c|}
\hline \multicolumn{4}{|c|}{ Capacity $(\mathrm{pc} / \mathrm{h})$} \\
\hline \multicolumn{4}{|c|}{ Conflicting Flow $=400 \mathrm{pc} / \mathrm{h}$} \\
\hline Lane & single & left & right \\
\hline HCM 2010 & 757 & 837 & 854 \\
\hline NCHRP 572 & $763(+0.68 \%)$ & $776(-7.33 \%)$ & $865(+1.27 \%)$ \\
\hline California & $961(+26.92 \%)$ & $1043(+24.62 \%)$ & $1134(+32.74 \%)$ \\
\hline North Tuscany & $1031(+36.10 \%)$ & $1046(+24.99 \%)$ & $1057(+23.80 \%)$ \\
\hline
\end{tabular}

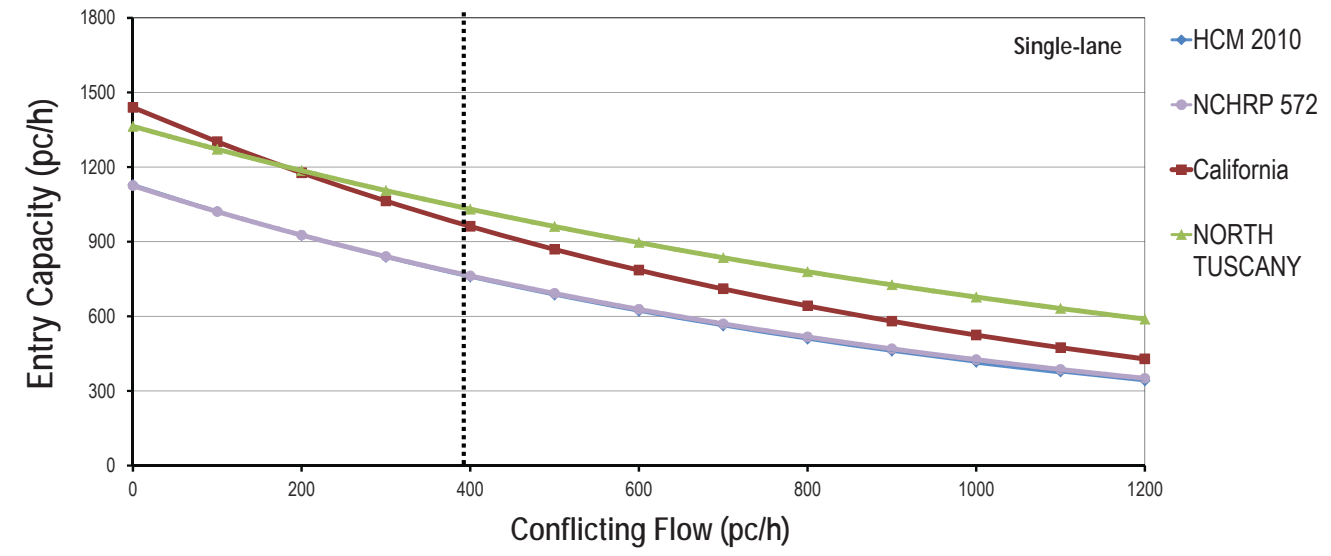

Figure 3: HCM 2010 roundabout capacity model calibration: single lane. 


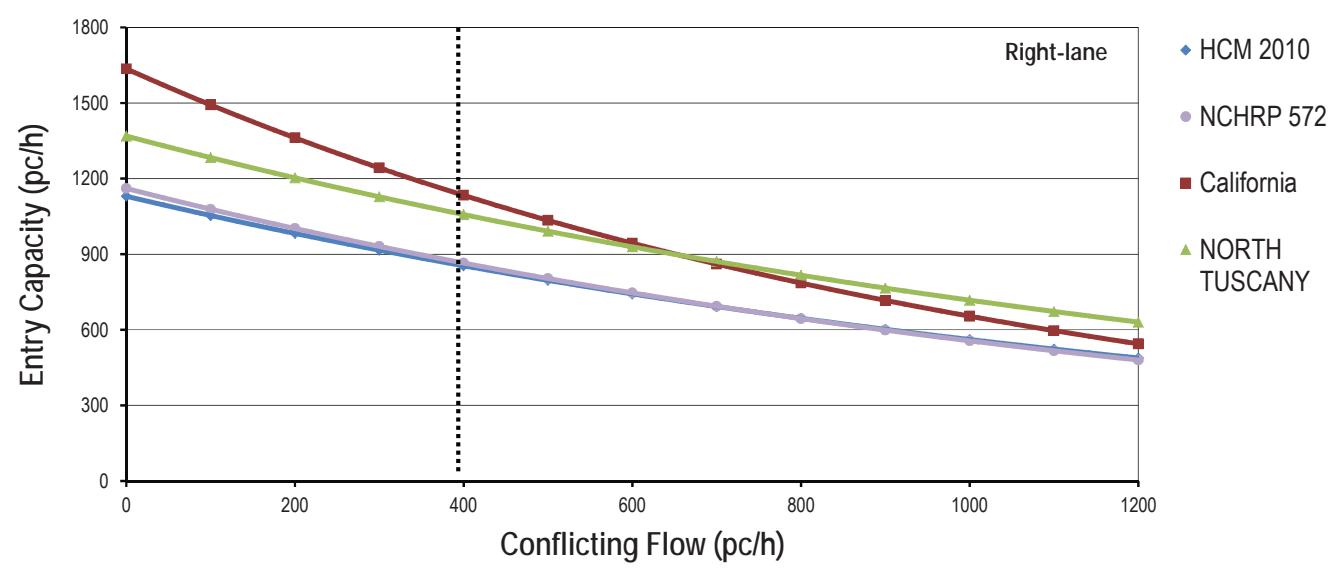

Figure 4: $\quad$ HCM 2010 roundabout capacity model calibration: right lane.

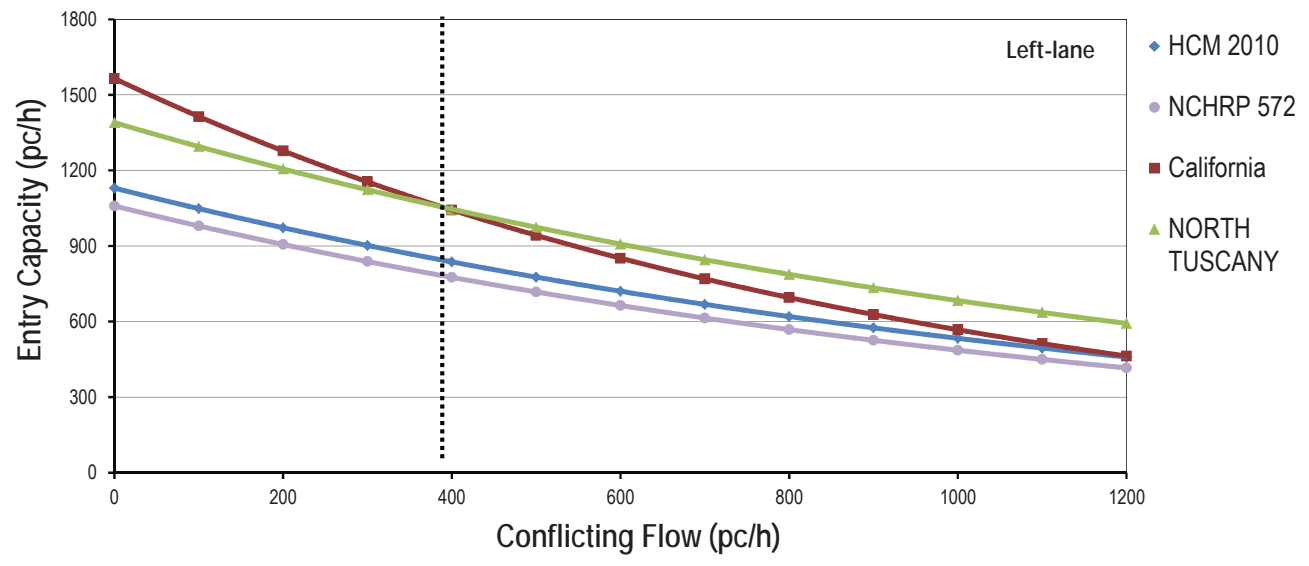

Figure 5: $\quad$ HCM 2010 roundabout capacity model calibration: left lane.

Several previous Italian studies have been conducted on critical gap analysis (e.g. [15]). However, this study represents the first following the NCHRP 572 headway data recording procedure recommended by HCM 2010. The herewith reported results are useful in HCM 2010 roundabout capacity model applications in Italy, with extensions to countries with similar driving habits and roundabout designs. For instance, the new data for the USA showed in the following section should be considered as preliminary and suggestive.

\section{Further research}

These first experimental results confirm that critical headway and follow-up headway are heavily influenced by driver behaviour and local habits. Moreover, the highlighted differences between Tuscany (Italy) and the United States suggest further field observations, to account for a wider range of local site conditions in order to improve the capacity model calibration, as recommended to by HCM 2010. Towards that goal, we have collected preliminary data from 
two additional US locations (Lexington, Kentucky and Kansas City, Kansas) and are beginning to analyse them.

Figure 6 illustrates the wide range of estimates for key parameters that may be obtained, further motivating the need for local calibration.

As demonstrated by this research, the median method is easier and faster than the maximum likelihood method while producing quite similar results. Such trend shall be checked in further research developments. Finally, as actual behaviour of entering drivers may be influenced by the presence of heavy/longer vehicles, this issue should be studied in depth. It is also possible that a simulation-based approach to roundabout capacity key parameters could be promising.

\section{Average Follow-upHeadway}

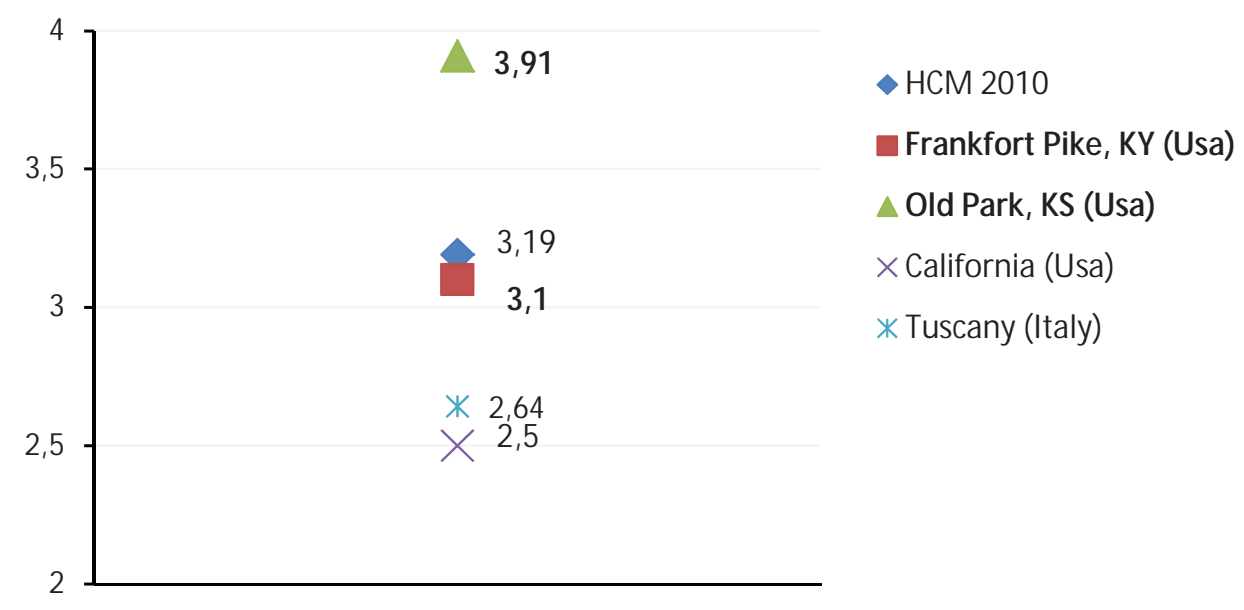

\section{Average Critical Headway}

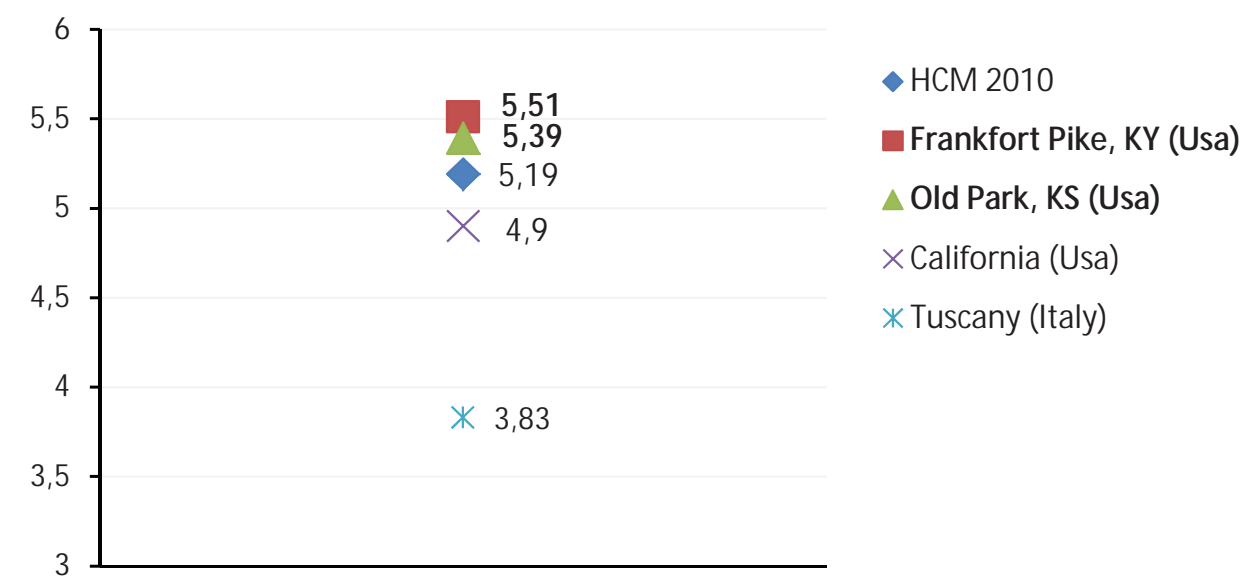

Figure 6: Estimates of critical and follow-up headway for two US locations. 


\section{Acknowledgements}

The authors gratefully acknowledge the assistance in Italian and US roundabout data collection respectively provided by Daniele Razzuoli of the University of Pisa, Eric Fitzsimmons of the University of Kansas and Teng (Alex) Wang, of the University of Kentucky.

\section{References}

[1] TRB, Highway Capacity Manual, N.R.C., Washington D.C., 2010.

[2] $\mathrm{Xu}, \mathrm{F}$. and Tian, Z.Z., Driver behaviour and gap acceptance characteristics at roundabouts in California. Journal of the Transportation Research Board, 207, pp. 117-124, 2008.

[3] TRB, NCHRP 572: Roundabouts in the United States, Washington D.C.

[4] Tian, Z.Z. et al., A further investigation on critical gap and follow up time. Proc. of the $4^{\text {th }}$ Int. Symp. On Highway Capacity, eds. TRB, National Research Council Elsevier: Washington, DC, pp. 397-408, 2000.

[5] Tian, Z. et al., Implementing the maximum likelihood methodology to measure a driver's critical headway. Transportation Research, Part A, pp. 187-197, 1999.

[6] Troutbeck, R.J., Estimating the critical acceptance gap from traffic movements, Queensland University of Technology, Australia, 1992.

[7] Brilon, W., Methods for measuring critical headway, Ruhr University, 1995.

[8] Weinert, A., Estimation of critical headways and follow-up times at rural unsignalized intersections in Germany, Bochum, Germany.

[9] SCILAB, http://www.scilab.org.

[10] Ferrari, P., Giannini, F., Ingegneria stradale: geometria e progetto di strade, ISEDI, pp. 228-230, 1994.

[11] Raff, M.S. and Hart, J.W, A volume warrant for urban stop signs. The Eno Foundation for Highway Traffic Control, 1950.

[12] Garber, N.J. and Hoel, L.A., Fundamental principles of traffic flow, West Publishing Comp., pp. 179-182, 1996.

[13] TRB, Highway Capacity Manual, Chpt. 21 and supplemental 33, N.R.C., Washington DC, 2010.

[14] Akcelik R., An assessment of the Highway Capacity Manual 2010 roundabout capacity, Peer reviewed papers for 3rd International Roundabouts Conference (http://teachamerica.com/RAB11/).

[15] Esposito T. et al., La determinazione dell'intervallo critico (Critical gap evaluation), Sistemi di Trasporto, vol. 20, n. 1, p. 10-20, 1997. 